Cadernos do IL $\odot$ Cadernos do IL $\odot$ Cadernos do IL $\quad \odot$ Cadernos do IL $\odot$ Cadernos do IL e Cadernos do IL

\title{
APRENDIZAGEM DE L2, MOTIVAÇÃO E IDENTIDADE: UM ESTUDO COM BRASILEIROS QUE RESIDEM NO EXTERIOR
}

\author{
Mailce Borges Mota (UFSC/CNPq) ${ }^{1}$ \\ Flavia Azeredo ${ }^{2}$
}

\begin{abstract}
RESUMO: Este estudo investiga a motivação para a aprendizagem de inglês como segunda língua (L2) a partir do Modelo de Auto-Sistema Motivacional na L2 (Dörnyei, 2005). O Modelo consiste em três componentes, sendo o self-ideal na L2 o componente mais importante para a sustentação do grau de motivação. Os participantes do estudo foram 5 brasileiros residentes nos Estados Unidos, na região de Washington, DC. Os dados foram coletados através de questionários e de narrativas orais sobre a aprendizagem de L2. Coletivamente, os resultados demonstram que, apesar do tempo em que estão em processo de aprendizagem, os participantes apresentam baixo grau de integratividade e não têm seu selfideal na L2 claramente definido.
\end{abstract}

PALAVRAS-CHAVE: Motivação - Possíveis selves - Aprendizagem de L2

ABSTRACT: This study investigates ESL learners' motivation within the L2 Motivational Self System framework (Dörnyei, 2005). The framework consists of three components, of which the ideal L2 self is the most important in the maintenance of motivation. Five Brazilian learners, living in the Washington DC area, participated in the study. The data was collected by means of questionnaires and oral narratives about L2 learning. Collectively, the results show that, despite the time these participants have been learning English, their degree of integrativeness is low and their ideal L2 self is not clearly defined.

KEYWORDS: Motivation - Possible selves - L2 learning

\section{INTRODUÇÃO}

A área de aprendizagem de L2 tem visto, sobretudo a partir da segunda metade da década de 1990 (Ortega, 2009), uma crescente necessidade de redefinir e de expandir alguns conceitos, tomados como tradicionais na literatura da área, à luz do conhecimento agora acumulado sobre a aprendizagem e sobre o uso de L2 (ver, por exemplo, Robinson, 2002; Sanz, 2005). Entre esses conceitos estão aqueles que dizem respeito às diferenças individuais, tanto no aspecto cognitivo - aptidão, capacidade de memória de trabalho, inteligência, noticing - quanto no aspecto afetivo - atitude, ansiedade e motivação (Dörnyei \& Skehan, 2003; Long \& Doughty, 2003). Sob a perspectiva de reconceptualização desses construtos o conceito de motivação, talvez por sua centralidade, tem sido o aspecto mais

\footnotetext{
${ }^{1}$ Dra. Universidade Federal de Santa Catarina / mailce@cce.ufsc.br

${ }^{2}$ Dra. Morgan State University / azeredoflavia@gmail.com
}

Cadernos do IL. Porto Alegre, n. .38 , junho de 2009. p. 22-42. 
estudado e sistematicamente pesquisado ao longo dos últimos anos. O interesse sobre o papel da motivação na aprendizagem de línguas provavelmente se deve ao fato de que essa variável de diferença individual se relaciona de forma decisiva com as demais.

Por exemplo, Dörnyei (2005) apresenta uma nova proposta teórica sobre motivação na aprendizagem de L2, reconfigurando o construto a partir de teorias psicológicas do self. Considerando teorias sobre motivação já consolidadas na área de L2 (Gardner \& Lambert, 1972; Gardner, 2001) e a evidência empírica que demonstra que existe relação entre motivação e a identidade do aprendiz, Dörnyei (2005) propõe uma conexão explícita entre o self do indivíduo em processo de aprendizagem e sua motivação (Dörnyei e Ushioda, 2009). Essa proposta está apresentada no Modelo de Auto-Sistema Motivacional na L2.

O Modelo tem se mostrado bastante promissor e tem estimulado a condução de vários estudos (ver, por exemplo, a coletânea organizada por Dörnyei e Ushioda, 2009). Uma grande parte deles é de natureza quantitativa e utiliza o questionário como instrumento principal. Entretanto, como apontam Kormos e Csizér (2008) e Csizér e Dörnyei (2005), ainda há a necessidade de estudos que investiguem a relação entre identidade e motivação em grupos de aprendizes com diferentes faixas etárias, em diferentes contextos de aprendizagem e em diferentes regiões geográficas por meio de métodos qualitativos.

De forma geral, a pesquisa sobre aprendizagem de inglês por alunos brasileiros concentra-se em ambientes instrucionais - essa pesquisa tem como foco ou populações de sala de aula no Brasil ou aprendizes que participam de programas de estudo em ambientes de segunda língua (L2). No presente estudo, investigamos a relação entre motivação e identidade na aprendizagem do inglês como L2. Os participantes deste estudo são brasileiros que escolheram residir nos Estados Unidos não pela aprendizagem do idioma, mas pelo objetivo de alcançar aprimoramento profissional ou de obter uma melhor condição sócio-econômica. Até onde sabemos, esta população - imigrantes brasileiros trabalhadores - geralmente, não é incluída em estudos sobre aprendizagem de L2 divulgados em nosso país. No que se segue, apresentamos uma breve revisão sobre o Modelo de Auto-Sistema Motivacional na L2, a metodologia empregada no estudo, a discussão dos resultados, seguida de nossas conclusões e sugestões para pesquisas futuras.

\section{REVISÃO DA LITERATURA}

Dörnyei (2005), amparado no trabalho intelectual de Markus e Nurius (1986), propõe um modelo de motivação para aprendizagem de L2 que reformula o próprio construto de motivação a partir da teoria psicológica de "possiveis selves"1. Como explicado por Ushioda e Dörnyei (2009), essa teoria faz uso da noção de possiveis selves para

\footnotetext{
${ }^{1}$ No original, possible selves (Ushioda \& Dörnyei, 2009:3).
}

Cadernos do IL. Porto Alegre, n. ${ }^{\circ} 38$, junho de 2009. p. 22-42. 
denominar o conjunto de idéias que o indivíduo tem sobre o que poderia se tornar, o que gostaria de se tornar e o que teme se tornar. Esta teoria, então, constrói uma relação entre o conceito de possiveis selves e motivação, argumentando que o repertório de possiveis selves de um indivíduo - ou seja, suas aspirações, objetivos de longo prazo, motivos, medos e ameaças - terá influência crucial sobre seu estado motivacional.

A proposta de Dörnyei de usar a teoria de possíveis selves como arcabouço para sua visão de motivação resulta do mega-estudo longitudinal que conduziu em parceria com Csizér, em 2002, sobre a atitude de alunos húngaros em relação à aprendizagem de L2. Dörnyei e Csizér (2002) investigaram as atitudes e motivações de 8.593 adolescentes entre 13 e 14 anos em relação à aprendizagem de cinco línguas estrangeiras na Hungria: inglês, alemão, francês, italiano e russo. Conduzido entre 1993 e 1999, o estudo mostrou que há cinco dimensões interrelacionadas na maneira como os aprendizes adolescentes húngaros abordam a aprendizagem daquelas línguas: integratividade, instrumentalidade, contato direto com falantes da L2, interesse cultural e vitalidade da comunidade falante da L2.

Especificamente com relação à integratividade, uma das dimensões com mais saliência no estudo, os autores concluíram que a característica multifacetada dessa variável, nos dados que recolheram, poderia ser explicada através da noção de identidade: para eles, o conceito de identidade está intimamente ligado ao conceito de integratividade, porque há uma espécie de identificação psicológica e emocional por parte do aprendiz com relação à L2, à cultura da L2 e aos falantes da L2. Nesse sentido, Dörnyei e Csizér (ibid.) propõem que o termo integratividade seja reexaminado e redefinido para incorporar a idéia de que ele expressa um processo básico de identificação do aprendiz a partir de seu self. Isso expande, e complexifica, a proposta inicial de Gardner (2001), que define integratividade como o interesse geral por aprender a L2 para se aproximar daquela comunidade.

Como sugerem Kormos e Csizér (2008), no mundo atual, e principalmente no caso da língua inglesa, não há mais uma comunidade falante que seja mais saliente que outra e, além disso, a identificação com falantes nativos não parece ser um fator motivacional de grande relevância para a maioria dos aprendizes de inglês como L2. Assim, ao redefinirem a noção de integratividade a partir do conceito de self, Dörnyei e Csizér (ibid.) colocam o indivíduo (o aprendiz) e seu mundo interior (seus possíveis selves) como o núcleo da relação entre motivação e aprendizagem e, dessa forma, dão ao fator identidade um papel de enorme relevância. Nessa reconfiguração, a noção de integratividade é proposta como o antecedente principal da motivação.

A partir dos resultados do estudo de 2002, Dörnyei (2005) desenvolve o "Modelo de Auto-Sistema Motivacional na L2", o qual é formado por três componentes principais: (1) O self-ideal na L2, (2) o self-obrigatório na L2 e (3) a experiência de aprendizagem da L2 ${ }^{2}$. O self-ideal na L2, como argumentado pelo autor, é o construto mais importante do Modelo, diz respeito à auto-imagem ideal que o aprendiz tem de si mesmo e expressa o

${ }^{2}$ No original, (1)ideal L2 Self, (2)Ought-to L2 Self, e (3)L2 Learning Experience (Dörnyei, 2005, p. 105-106).

Cadernos do IL. Porto Alegre, n. .38 , junho de 2009. p. 22-42. http://www.seer.ufrgs.br/cadernosdoil/ 
desejo (ou a falta dele) de se tornar um falante competente na L2. O self-obrigatório na L2 diz respeito aos atributos que o aprendiz julga ter de possuir para que evite resultados negativos em sua aprendizagem. Por fim, o terceiro componente - experiência de aprendizagem da L2 - refere-se a fatores situacionais específicos, relacionados ao ambiente de aprendizagem e de experiências (Dörnyei, ibid, p. 106; Kormos e Csizér, ibid., p. 331).

O modelo proposto por Dörnyei (ibid.) também se ampara no trabalho de Higgins (1987), o qual sugere que a motivação resulta do desejo do indivíduo em diminuir a discrepância entre o seu self-ideal (i.e., o que o indivíduo gostaria de se tornar) e seu selfreal. A motivação também resulta do desejo que o indivíduo tem de diminuir a distância entre o seu self-real e o seu self-obrigatório (ou seja, a percepção que temos sobre o que os outros esperam que nos tornemos).

O componente self-ideal, no modelo de Dörnyei, inclui a dimensão integratividade, que é proposta como parte da motivação integrativa no modelo de Gardner (2001, por exemplo). Em Gardner (ibid.), a dimensão integratividade engloba a orientação integrativa, o interesse pela L2 e as atitudes em relação à comunidade falante da L2, inclusive o interesse, por parte do aprendiz, de interagir socialmente com os membros de outros grupos lingüísticos (Dörnyei, ibid., p. 68). No Modelo de Auto-Sistema Motivacional na L2, o conceito de integratividade está incorporado no componente self-ideal, porque este componente inclui a visão que o aprendiz tem de si mesmo como falante competente e essa visão faz referência aos falantes nativos dessa $\mathrm{L} 2$.

Tomando como ponto de partida o Modelo de Auto-Sistema Motivacional na L2, o qual, como mostrado, relaciona a motivação para aprender a L2 com a noção de identidade, nosso objetivo no presente estudo é investigar essa relação no caso de brasileiros, aprendizes de inglês como L2, que residem nos Estados Unidos. Especificamente, nosso interesse é detectar como os possíveis selves emergem nesse contexto. Para tanto, escolhemos coletar os dados através da adaptação do questionário proposto por Dörnyei e Clément (2001), que será descrito na seção Método, e através de narrativas autobiográficas.

Como apontado por vários pesquisadores (por exemplo, Cotterall, 2008; Kalaja, Menezes e Barcelos, 2008), as narrativas produzidas por aprendizes de L2 podem ser de grande valor para a compreensão dos processos de aprendizagem. Pavlenko (2007) sugere que as narrativas autobiográficas fazem três contribuições importantes. Primeiro, elas nos permitem ter uma visão do mundo privado de cada pessoa, o que não é possível através de pesquisas experimentais. Segundo, as narrativas dão saliência às relações novas entre vários processos de aprendizagem e vários fenômenos, o que pode nos apontar futuros caminhos para pesquisa. Finalmente, as narrativas são fontes ricas de informação para estudos de natureza sociolingüística, inclusive aqueles históricos e diacrônicos, principalmente em contextos em que outras fontes são escassas. Da mesma forma, Cotterall (2008, p. 127) sugere que a eliciação de narrativas parte do princípio de que os aprendizes são indivíduos completos e complexos, permitindo que eles se apresentem em toda a sua imprecisão e

Cadernos do IL. Porto Alegre, n. ${ }^{\circ} 38$, junho de 2009. p. 22-42. http://www.seer.ufrgs.br/cadernosdoil/ 
idiossincrasia. Assim, para complementar o questionário sobre motivação, optamos pelo uso de narrativas autobiográficas por elas serem uma janela através da qual podemos observar o mundo interior do aprendiz e, dessa forma, obter uma melhor compreensão da relação entre este complexo fator e questões de identidade.

\section{MÉTODO}

\section{PERGUNTA DE PESQUISA}

Este estudo procura responder a seguinte pergunta de pesquisa: qual é a relação entre a motivação para aprender inglês e a identidade dos aprendizes, aqui definida em termos de possíveis selves?

\section{PARTICIPANTES}

O estudo foi conduzido com 5 participantes, todos falantes nativos de português brasileiro que, à época da coleta de dados, residiam na região de Washington, DC. As informações biográficas sobre cada participante foram coletadas através de um questionário demográfico (Apêndice A) e são apresentadas a seguir.

Participante 1, do sexo feminino, não nos informou a idade por razões pessoais. À época da coleta de dados residia há 5 anos nos Estados Unidos. Possui ensino superior completo e antes de mudar-se para os Estados Unidos morava no Ceará. No Brasil, teve experiência com a aprendizagem do inglês na escola pública e, paralelamente, em curso livre de idiomas.

Participante 2, do sexo feminino, 32 anos. Quando da coleta de dados, residia há 4 anos nos Estados Unidos. Possui o ensino médio completo. Antes de mudar-se para os Estados Unidos, morava no Estado de Goiás. No Brasil, teve experiência com a aprendizagem do inglês na escola pública, durante o ensino fundamental e médio.

Participante 3, do sexo feminino, 46 anos. À época da coleta de dados, residia há 6 anos nos Estados Unidos. Possui o ensino superior completo e, antes de mudar-se, morava no Rio de Janeiro. No Brasil, teve experiência com a aprendizagem do inglês durante o seu curso de graduação e, posteriormente, em curso livre de idiomas.

Participante 4, do sexo masculino, 59 anos. Quando de sua participação no estudo, residia há 6 meses nos Estados Unidos. Possui pós-doutorado em sua área de pesquisa e antes de mudar-se para os Estados Unidos morava em Santa Catarina. No Brasil, teve experiência

Cadernos do IL. Porto Alegre, n. ${ }^{\circ} 38$, junho de 2009. p. 22-42. 
com a aprendizagem do inglês durante o curso de mestrado, realizado em universidade pública e, posteriormente, em curso livre de inglês no Brasil e no exterior.

Participante 5, do sexo masculino, 34 anos. À época da coleta de dados, residia há 5 anos nos Estados Unidos. Possui pós-doutorado em sua área de pesquisa e antes de mudar-se para os Estados Unidos morava em Minas Gerais. No Brasil, teve experiência com a aprendizagem do inglês durante toda a sua vida escolar e freqüentou cursos livres de língua inglesa em escolas no Brasil e no exterior.

\section{INSTRUMENTOS}

Além do questionário demográfico, um questionário sobre motivação, adaptado de Dörnyei e Clement (2001) foi aplicado. Este questionário (Apêndice B) foi utilizado no estudo que deu origem ao Modelo de Auto-Sistema Motivacional na L2. O questionário tem sido extensivamente adaptado e empregado em trabalhos recentes sobre motivação na aprendizagem de L2 (Csizér e Dörnyei, 2005; Kormos e Csizér, ibid.; Ryan, 2009) e consiste em três seções. Na Seção I, com 21 itens, os participantes foram solicitados a expressar sua opinião sobre várias línguas, inclusive a língua portuguesa, em uma escala Likert de 1 a 5 pontos, sendo 5 a opinião mais positiva e 1 a mais negativa. Os itens desta Seção abordam os seguintes aspectos: razões para aprender a L2, atitudes em relação a L2, intenção de esforço para aprender a L2, proficiência de familiares. Ou seja, nessa Seção estão as dimensões integratividade, instrumentalidade, interesses culturais e vitalidade da comunidade falante da L2.

Na Seção II, com 7 itens, os participantes foram solicitados a expressar sua opinião sobre várias afirmações, em uma escala de concordância. Os itens abordavam aspectos relacionados ao grau de autoconfiança na aprendizagem e uso da L2, às atitudes dos participantes e de seu meio social para com a aprendizagem, inclusive na escola e à assimilação da língua e da cultura.

A Seção III do questionário, com 7 perguntas abertas e uma de múltipla escolha, contém questões sobre opção lingüística bem como solicita informações pessoais dos participantes.

\section{PROCEDIMENTOS}

Após lerem e assinarem um termo de consentimento, os participantes foram solicitados a responder o questionário e a fazer uma narrativa oral espontânea em português sobre seu processo de aprendizagem de língua inglesa, desde o inicio desse processo até $o$ presente momento. $\mathrm{O}$ enunciado desencadeador da narrativa foi "Conte-me como foi o seu processo de aprendizagem de inglês desde o início, quando você começou a aprender, até o presente momento". Os participantes foram informados de que poderiam falar pelo tempo

Cadernos do IL. Porto Alegre, n. ${ }^{\circ} 38$, junho de 2009. p. $22-42$. 
que desejassem. Para alguns participantes, perguntas adicionais foram feitas a fim de estimulá-los a narrar. Os dados foram coletados individualmente e as narrativas foram gravadas na presença de uma das autoras, sendo posteriormente, transcritas por elas. Todas as informações que pudessem levar à identificação dos participantes foram omitidas na análise das transcrições.

\section{RESULTADOS E DISCUSSÃO}

Como mencionado anteriormente, a Seção I do questionário sobre motivação trata da opinião dos participantes acerca de fatores relacionados à integratividade, à instrumentalidade, aos interesses culturais e à vitalidade da comunidade falante da L2. Essa Seção está constituída por 21 itens, os quais podem ser verificados no Apêndice B. A Figura 1 apresenta os resultados para os itens 1-10.

\begin{tabular}{l|l|l|l|l|l|l|l|l|l|l|l|l|l|l|l|l|l|l|l|l|l|l|l|l|l|}
\hline & \multicolumn{10}{|c|}{ P1 } & \multicolumn{1}{c|}{ P2 } & \multicolumn{1}{c|}{ P3 } & \multicolumn{6}{c|}{ P4 } & \multicolumn{5}{c|}{ P5 } \\
\hline $\begin{array}{l}\text { Q } \\
\mathbf{1}\end{array}$ & A & P & I & I & F & A & P & I & I & F & A & P & I & I & F & A & P & I & I & F & A & P & I & I & F \\
\hline $\mathbf{2}$ & 3 & 5 & 4 & 5 & 3 & 2 & 5 & 2 & 3 & 3 & 3 & 4 & 5 & 4 & 5 & 3 & 5 & 3 & 5 & 3 & 2 & 3 & 2 & 2 & 2 \\
\hline $\mathbf{3}$ & 4 & 3 & 3 & 5 & 2 & 3 & 4 & 3 & 5 & 3 & 4 & 3 & 3 & 5 & 5 & 4 & 4 & 3 & 5 & 4 & 3 & 2 & 2 & 5 & 4 \\
\hline $\mathbf{4}$ & 4 & 4 & 4 & 4 & 4 & 3 & 4 & 3 & 5 & 3 & 4 & 4 & 4 & 4 & 4 & 5 & 5 & 5 & 5 & 5 & 5 & 5 & 5 & 5 & 5 \\
\hline $\mathbf{5}$ & 2 & 5 & 2 & 5 & 2 & 2 & 4 & 2 & 4 & 2 & 2 & 4 & 2 & 5 & 4 & 1 & 1 & 1 & 5 & 1 & 2 & 2 & 2 & 3 & 2 \\
\hline $\mathbf{6}$ & 2 & 2 & 2 & 5 & 2 & 3 & 5 & 3 & 4 & 3 & 4 & 4 & 3 & 5 & 4 & 1 & 1 & 1 & 5 & 1 & 4 & 2 & 4 & 5 & 4 \\
\hline $\mathbf{7}$ & 3 & 5 & 3 & 5 & 3 & 3 & 5 & 3 & 5 & 3 & 5 & 5 & 5 & 5 & 5 & 3 & 1 & 3 & 5 & 3 & 2 & 2 & 2 & 5 & 2 \\
\hline $\mathbf{8}$ & 2 & 3 & 2 & 2 & 2 & 2 & 4 & 2 & 2 & 2 & 2 & 4 & 2 & 2 & 2 & 1 & 5 & 1 & 5 & 3 & 2 & 5 & 2 & 5 & 2 \\
\hline $\mathbf{9}$ & 5 & 3 & 2 & 2 & 2 & 2 & 3 & 2 & 5 & 2 & 5 & 5 & 5 & 5 & 5 & 1 & 5 & 1 & 1 & 1 & 2 & 5 & 2 & 5 & 1 \\
\hline $\mathbf{1 0}$ & 2 & 5 & 2 & 5 & 2 & 3 & 4 & 3 & 4 & 3 & 4 & 4 & 4 & 4 & 4 & 5 & 1 & 5 & 5 & 5 & 2 & 2 & 2 & 2 & 2 \\
\hline
\end{tabular}

Figura 1: Questionário de motivação Seção 1 perguntas $(\mathrm{P})$ de 1 a 10

Como pode ser observado, com relação ao aspecto integratividade (tratado nas perguntas 2, 4, 6, 7 e 10 do questionário), os participantes tendem a demonstrar, em geral,

Cadernos do IL. Porto Alegre, n. ${ }^{o}$ 38, junho de 2009. p. 22-42. 
opinião mais positiva com relação às línguas inglesa e portuguesa. Para eles, saber inglês e português contribuiria para seu conhecimento em geral. Entretanto, também acreditam que para conhecer a cultura e a arte dos falantes das línguas apresentadas no questionário é importante aprender as referidas línguas, sendo que, para isto, não apontam diferença significativa entre as línguas. Nesse item, com exceção do Participantes 2 (P2), todos os participantes atribuíram o mesmo grau de importância a todas as línguas mencionadas no questionário. Esses resultados podem indicar que, em se tratando de cultura e de arte relacionadas a uma língua, saber a língua é relevante, independentemente da língua.

Com relação à utilidade das línguas para viagens ao exterior, os participantes mostraram que é o inglês a língua mais relevante. Para o desenvolvimento profissional, atribuem maior importância para o inglês e para o português, sendo que P3 indica que todas as línguas apresentadas no questionário são importantes para seu crescimento profissional.

Finalmente, para o item 10, que trata explicitamente de uma questão de identidade, os participantes tendem a demonstrar uma maior atitude positiva em relação à língua inglesa - pois, como os dados indicam, parecem ter o desejo de falar como os nativos dessa língua. Entretanto, eles também expressam atitude favorável com relação às demais línguas estrangeiras, que guardam posição similar com relação ao português. Três participantes, P3, P4 e P5, atribuíram, cada um, os mesmos valores para todas as línguas estrangeiras, embora não sejam falantes do alemão, do francês e do italiano, sendo que P4 e P5 parecem não ter o desejo de soar como um falante de língua portuguesa, e P5 parece não atribuir relevância à ideia de soar como um falante nativo de qualquer língua estrangeira. Como dito anteriormente, a noção de integratividade é incorporada, por Dörnyei, ao self ideal. O antecedente principal da motivação é a integratividade, e o antecedente principal desta é a atitude. Assim, podemos dizer que o self ideal de nossos participantes inclui uma atitude positiva em relação à língua inglesa, sim, mas essa atitude é apenas relativamente positiva (em comparação a uma atitude altamente positiva ou marcadamente diferente daquela em relação às outras línguas do questionário). Com base nos resultados para os itens analisados, podemos dizer que a língua inglesa não tem posição de muito mais destaque que as demais, o que, a nosso ver, indica um grau pouco saliente de integratividade. Se, como afirma Dörnyei (2005, 2009), o self ideal, que incorpora a dimensão integratividade, é um poderoso elemento motivador da aprendizagem de línguas, porque expressa o desejo de reduzir a distância entre o que o aprendiz é e o que deseja vir a ser como falante da L2, podemos dizer que a motivação de nossos participantes parece estar afetada por esse grau de disposição integrativa, que é apenas relativo. Ou seja, até esse ponto da análise, o self ideal de nossos participantes na língua inglesa não parece estar completamente constituído de modo a motivá-los de forma significativa para aprender a L2, mas parece estar em processo de constituição.

Essa interpretação parece ser corroborada pelos resultados obtidos para o item 1, em que os participantes tendem a atribuir valores altos para o seu grau de aceitação da língua inglesa, não só demonstrando uma atitude muito positiva com relação à língua, mas

Cadernos do IL. Porto Alegre, n. ${ }^{\text {o } 38, ~ j u n h o ~ d e ~ 2009 . ~ p . ~ 22-42 . ~}$

$$
\text { http://www.seer.ufrgs.br/cadernosdoil/ }
$$


também atribuindo grande valor ao português, cujo resultado é melhor do que o inglês, como é de se esperar. Com relação à importância da língua inglesa no mundo atual, os participantes são unânimes na opinião de que esta é muito relevante, reconhecem o papel ainda relativo da língua portuguesa no cenário internacional e a importância de línguas como o francês e o alemão nesse cenário. Todos os participantes expressam uma atitude positiva com relação ao grau de esforço que estão determinados a empregar para aprender a língua inglesa, principalmente em relação às outras línguas estrangeiras. Participante 5, entretanto, atribui valor médio ao seu grau de esforço pretendido. Por fim, com relação à influência da proficiência de familiares próximos, os participantes reportaram maior proficiência na língua inglesa, em comparação às demais línguas estrangeiras, com valores ligeiramente superiores para pai/marido.

Coletivamente, os dados dessa Seção demonstram que o grau de integratividade dos participantes, um dos antecedentes mais importantes para a motivação na aprendizagem de L2, é relativo, em comparação às outras línguas estrangeiras. Ortega (2009) sugere que indivíduos motivados para aprender uma L2 tem os antecedentes da motivação (integratividade, instrumentalidade, atitudes positivas em relação ao falante e à cultura da L2) todos muito salientes. Isso acontece porque esses indivíduos têm o self-ideal na L2 bem desenvolvido. No caso de nossos participantes, não temos evidência clara sobre a uniformidade da saliência desses antecedentes, o que nos leva a propor que o self-ideal na L2 ainda está em processo de formação.

A Figura 2 apresenta os resultados obtidos para os itens 11-21 da Seção 1.

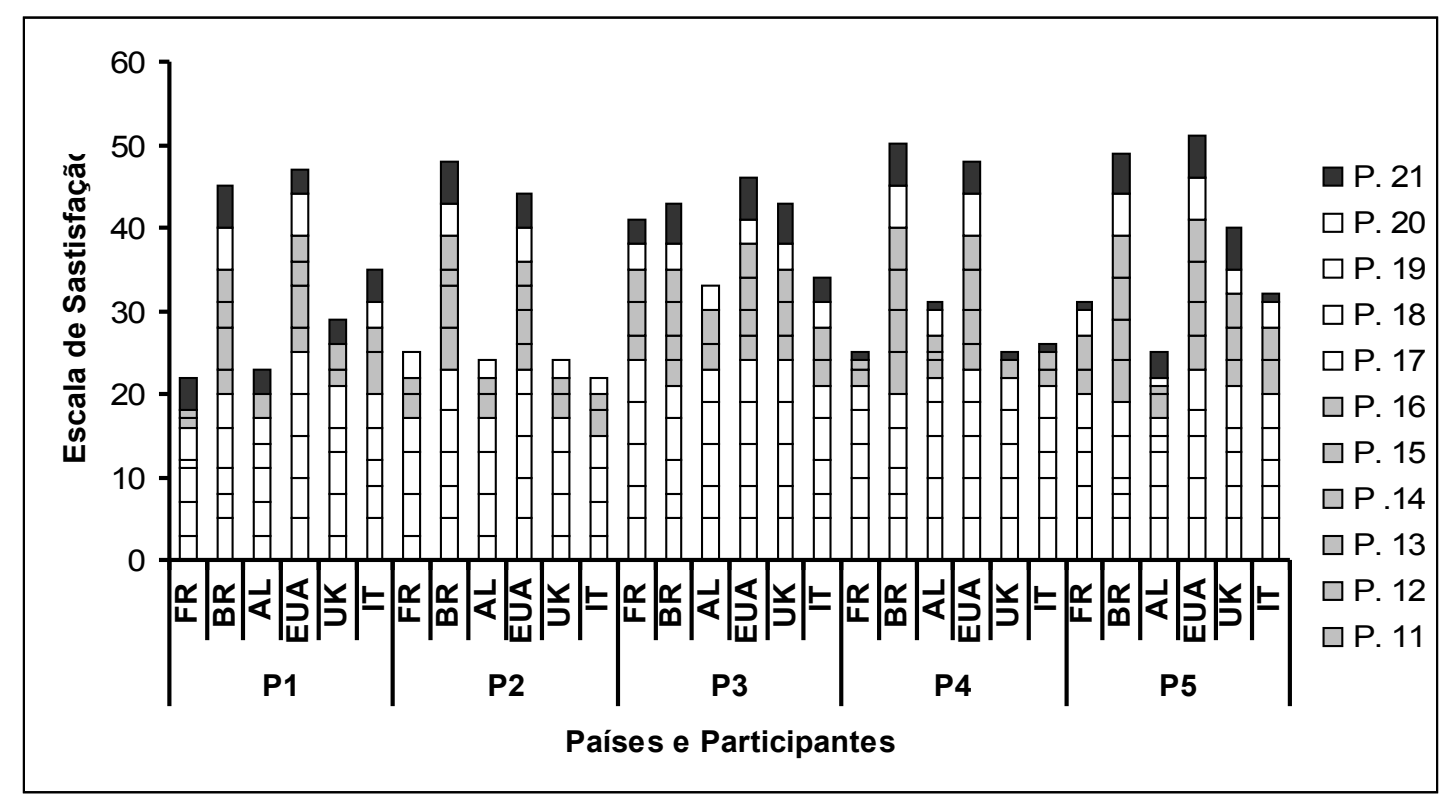

Figura 2: Questionário de motivação Seção 1 perguntas de 11 a 21

Cadernos do IL. Porto Alegre, n. ${ }^{\circ} 38$, junho de 2009. p. 22-42. http://www.seer.ufrgs.br/cadernosdoil/ 
Estes itens da Seção 1 abordam as atitudes dos participantes em relação às comunidades e os falantes das línguas mencionadas no questionário (itens 11 e 17), a importância internacional que atribuem a essas comunidades (itens 12 e 13) e a quantidade itens 18 e 20$)$ e a qualidade $(14,15,16,19$ e 21$)$ do contato que os participantes têm com a L2 e seus falantes.

De forma geral, os participantes demonstram uma atitude positiva em relação às diversas comunidades apresentadas, de modo que não podemos afirmar preferência por países falantes de língua inglesa. No entanto, a atitude com relação aos falantes dessas comunidades demonstra uma certa preferência pelo Brasil e pelos Estados Unidos. A importância internacional que atribuíram a essas comunidades é coerente com uma percepção de que Alemanha, França, Estados Unidos e Inglaterra são países com situação sócio-econômica privilegiada, sendo que a Itália, seguida do Brasil recebeu a menor pontuação no item 12. O Brasil, na opinião desses participantes, tem um papel de menor relevância no contexto mundial, em comparação com os outros países apresentados. A importância atribuída aos Estados Unidos, país onde residem, em termos de seu papel internacional é coerente com os demais itens que abordam atitudes em relação à língua inglesa e às comunidades falantes dessa língua.

Com relação à quantidade de contato com as línguas e com seus falantes, os resultados mostram que, para os participantes, esse contato é relativamente alto para a língua inglesa, em relação às outras línguas estrangeiras, mas é também igualmente alto para a língua portuguesa. Os itens dedicados à qualidade do contato mostram que essa é alta para a língua inglesa, o que é de fato esperado, mas a qualidade do contato com a língua portuguesa, principalmente através de mídias, é reportada como superior pelos participantes. Juntos, esses resultados podem ser tomados como indicação de que, ao contrário do que se comumente acredita, mesmo em situação de imersão, a qualidade e a quantidade de contato e de exposição à língua materna, para esses participantes, é muito alta quando comparada à língua inglesa.

O contato com a L2, como sabemos, é uma variável fundamental no processo de aprendizagem e tem relações complexas com a motivação do indivíduo. Por exemplo, Dörnyei e Csizér (ibid.) mostram que quanto mais freqüente o contato com a L2, mais autoconfiança sobre sua competência comunicativa o aprendiz desenvolve e isso tem um efeito benéfico sobre a aprendizagem. Isabelle-Garcia (2006) mostra que, em situações de imersão, a aquisição da L2 sofre considerável influência da relação complexa entre motivação, aculturação e desenvolvimento de redes sociais. Para otimizar o ambiente de aprendizagem, é preciso haver interação equilibrada entre essas três variáveis. No caso de nossos participantes, é possível que o contato com a língua portuguesa, declarado como de qualidade superior àquele com a língua inglesa, tenha relação com o grau de motivação para aprendizagem do inglês. Juntas, essas duas variáveis podem afetar de forma negativa o desenvolvimento da competência comunicativa.

Cadernos do IL. Porto Alegre, n. ${ }^{\circ} 38$, junho de 2009. p. 22-42. 
A Seção 2 do questionário trata de questões relacionadas às atitudes dos participantes e de seu meio social para com a aprendizagem de L2 (item 23), inclusive na escola (itens 24 e 26), a assimilação da língua e da cultura (itens 25 e 27) e a auto-confiança do indivíduo na aprendizagem e uso da L2 (itens 22 e 28). Os resultados dessa Seção estão apresentados na Figura 3.

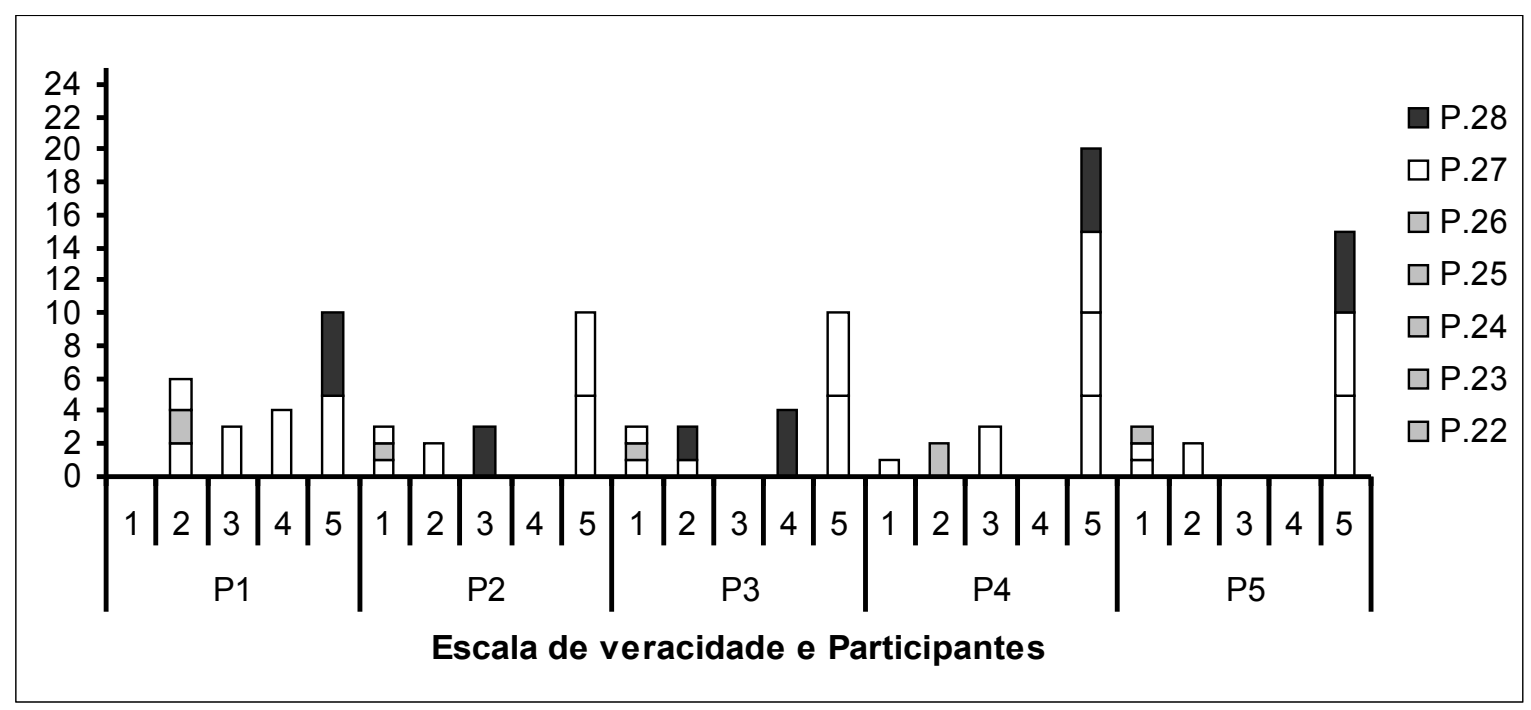

$1=$ com certeza não é verdade $2=$ não é verdade $3=$ parte verdade, parte mentira $4=$ quase verdade $5=$ verdade Figura 3: Questionário de motivação Seção 2 perguntas de 22 a 28

Com relação ao item auto-confiança, os participantes tendem a achar que a tarefa de aprender uma L2 é difícil, mas a percepção que têm de sua capacidade de engajar-se em comunicação com outras pessoas em uma L2 tende a ser positiva. O meio social em que os participantes estão inseridos valoriza o conhecimento de uma L2, conforme pode ser observado nos resultados para a questão 23 . Esse resultado é importante na medida em que o item está inserido na dimensão atitudes em relação à L2, o que é um dos antecedentes da integratividade, ela mesma um antecedente da motivação. A atitude positiva em relação à L2 é mantida nas questões 24 e 26, em que se evidencia a valorização do ensino de L2 na escola por eles e por seus familiares. Em termos de assimilação, os participantes revelam uma postura igualmente positiva e não expressam medo de perder sua cultura e a língua materna.

Como dito anteriormente, a Seção 3 do questionário trata de informações pessoais e a opção linguística dos participantes, sendo este o item que cabe ser analisado no presente estudo. Assim, quando indagados sobre as três línguas que, em grau de importância, gostariam de aprender (em questão aberta), 4 dos 5 participantes apontaram o inglês como a língua mais importante, sendo que o participante 4 apontou o chinês. Houve uma certa variação nas línguas estrangeiras indicadas como segunda e terceira opções, mas, para essas

Cadernos do IL. Porto Alegre, n. ${ }^{\circ} 38$, junho de 2009. p. 22-42. 
respostas, os participantes reafirmam seu interesse por línguas mais comumente ensinadas (espanhol, italiano, francês).

Retomando a questão levantada anteriormente sobre o grau de integratividade demonstrado e o papel que essa variável tem na construção do self-ideal na L2 e, portanto, na motivação para aprendizagem, a análise das seções 2 e 3 do questionário corrobora nossa interpretação de que os participantes do estudo estão em processo de construção de seu self-ideal na L2. O grau de integratividade na aprendizagem da língua inglesa não está claramente distinto de outras línguas estrangeiras. $\mathrm{O}$ fato de que eles têm, de modo geral, uma atitude positiva em relação à L2 (inglês) é também tomado como evidência desse processo de construção, pois a atitude é um dos antecedentes da integratividade, como já apontado.

Outro antecedente importante, nesse contexto, é a instrumentalidade. Essa variável foi tratada nas questões 6 e 7 (Seção 1) do questionário, embora de maneira superficial. Ainda assim, é possível ver que os participantes atribuem importância à língua inglesa por razões pragmáticas relacionadas ao seu crescimento profissional e cultural. Nesse sentido, a instrumentalidade, como apontado por Dörnyei (2009), integra o self-ideal na L2.

O Modelo de Auto-Sistema Motivacional na L2 possui três componentes. No presente estudo, não encontramos evidência, através do questionário aplicado, para o componente self-obrigatório. Entretanto, através das narrativas dos participantes podemos tratar de um elemento constitutivo do Auto-Sistema Motivacional de fundamental importância - a experiência de aprendizagem na L2. De fato, na apresentação mais recente de seu modelo, Dörnyei (ibid., p. 29) afirma que o self-obrigatório se distingue dos dois outros componentes. Entre seus elementos constitutivos estão o ambiente de aprendizagem em que o indivíduo está inserido e sua experiência de aprendizagem, o que inclui fatores como o impacto do professor, o currículo escolar, o grupo de colegas e as experiências de sucesso. $\mathrm{O}$ autor ressalta que esse é um componente que ainda precisa ser mais detalhado, especificamente no que diz respeito ao construto do self.

Embora o elemento experiência de aprendizagem da L2 não esteja completamente desenvolvido no Modelo, é de nossa opinião que as narrativas produzidas pelos participantes sejam particularmente iluminadoras para melhorar nossa compreensão sobre a relação entre motivação e identidade.

Retomando a pergunta de pesquisa deste estudo - qual é a relação entre a motivação para aprender inglês e a identidade dos aprendizes, aqui definida em termos de possíveis selves? - podemos afirmar, com base na análise dos questionários, que, para os participantes, o self-ideal na L2 está na melhor das hipóteses, em processo de construção. Dado o tempo de permanência em contexto de imersão e a relativa experiência de aprendizagem de língua inglesa que os participantes reportaram ter, cabe explorar a razão pela qual essa construção ainda estava em desenvolvimento. Estes são aprendizes que demonstram atitudes positivas em relação à L2, interesse pela aprendizagem, instrumentalidade, mas apenas relativa integratividade, a força motriz da motivação. As

Cadernos do IL. Porto Alegre, n. ${ }^{\text {o } 38, ~ j u n h o ~ d e ~ 2009 . ~ p . ~ 22-42 . ~}$ 
narrativas nos mostram uma possibilidade de resposta, já que através delas podemos perceber que suas experiências de aprendizagem nem sempre são bem sucedidas, como ilustram os relatos a seguir:

P1 - sobre sua aprendizagem no Brasil: Nas escolas eu estudava mas, era aquela coisa assim ... pensava que nunca ia precisar então não me interessava. Eu não fiz nenhum curso assim... (bom) no Brasil... colocava na cabeça que não ia precisar do inglês então não prestava muita atenção. Hoje me arrependo por que se tivesse aprendido o básico eu estaria melhor, mais bem, né.

P1 - sobre sua situação atual: O meu inglês tá mais ou menos. Não tá bom, não. Eu consigo me comunicar um pouquinho. No começo eu falava que não falava inglês agora eu tento, né. Eu tento ... eu não entendo ou a pessoa não entende, mais aí faz gestos ... mas com certeza eu vou conseguir esse inglês. Eu vou aprender esse inglês. Agora eu vou começar estudar de novo."

P2 - sobre sua situação atual: Aqui, morando nos EUA tenho passado por alguns cursos mas, como eu não me comunico diariamente com as pessoas em inglês falo muito ainda com as pessoas em português e espanhol, tem dificultado meu aprendizado. Ai .... (suspirou... com exaustão) Aqui ta difícil ... é ... é muito diferente. A verdade é essa. Quando você tá no SEU PAÍS as pessoas têm uma disposição de, por exemplo, alguém que é de fora tem uma disposição diferente de te ouvir e procurar a te entender, então você acha que está falando bem inglês. E aqui você entra com a questão do dia a dia, que as pessoas não têm tanta paciência. Se você pergunta mais de uma vez a mesma coisa elas se irritam com você, então isso tudo dificulta um pouco o nosso aprendizado. Você tem que pegar mais, você tem que ouvir mais, aprender certas expressões. Eu acredito que minha dificuldade está sendo primeiro, porque eu não falo inglês todos os dias com as pessoas; eu não sou obrigada a me forçar e o segundo, as poucas oportunidades que tenho eu percebo que as pessoas não têm paciência então você se intimida um pouco em estar enfrentando.

P 3 - sobre sua aprendizagem: Assim que entrei na faculdade fiz inglês sim ... mas eu acho que se eu fosse mais nova eu pegaria com mais facilidade e também eu estava na faculdade. A faculdade já era pesada, depois tive que fazer estágio, dai casei cedo então assim não era o foco ... a primeira prioridade... tinham outras coisas em volta mas, sempre com a necessidade de aprender mas, como já tinha aquele inglesinho básico de fazer compras me virava, mas não era um estudo sério da língua o que hoje em dia vejo que é extremamente necessário pra mim.

P4 - sobre sua situação atual: Agora aqui nos Estados Unidos comecei a fazer um curso, dois cursos de inglês, na verdade, um de pronúncia e outro de escrita, mas acabei também desistindo dos dois. Foi agora então aqui, estou aqui há 6 meses, mas também não estou fazendo nenhum curso regular, comprei algum material mas também não estou utilizando sistematicamente. Então, resumindo, posso dizer com toda a segurança, eu nunca fiz um

Cadernos do IL. Porto Alegre, n. ${ }^{o}$ 38, junho de 2009. p. 22-42.

http://www.seer.ufrgs.br/cadernosdoil/ 
ano de inglês seguido, regular, durante um ano, nunca. Eu aprendi lendo e isso tem me atrapalhado muito porque eu aprendi a pronúncia muito errada, aprendi o sentido das palavras, mas não a pronúncia e isso dificulta a minha comunicação com os outros. Acho que é isso, deu. Então, considerando que eu comecei lá no mestrado, na década de 80, eu estou me debatendo com o inglês já há 30 anos. Uma coisa relevante nessa história é que naquela época o inglês não era tão importante como é agora. Agora quem não sabe inglês é quase analfabeto. Naquela época não.

P5 - sobre sua situação atual: A minha mãe e meu pai me colocaram num curso de inglês, mas, eu nunca me dei muito bem com o curso de inglês eu faltava muito, eu não fazia nenhum para casa e assim nunca me senti muito interessado a saber ...Quando eu cheguei aqui... com um inglês terrivel... eu não conseguia falar quase nada. Agora melhorou um pouquinho mas, mesmo assim eu não vejo grandes melhoras ... e eu não acho que vai haver grandes melhoras não. A forma de eu melhorar o meu inglês é se eu voltasse a fazer algum curso aqui nos Estados Unidos e ter um professor para me dar tarefa, me corrigir os erros. No laboratório onde eu trabalho eu falo inglês o tempo todo, mas as pessoas não me corrigem. Eu tenho as minhas dificuldades para falar mas, todo mundo entende o que eu quero dizer ... assim eu não sei os erros que eu estou cometendo, eu acho que isso seria importante.

Coletivamente, os excertos acima mostram que esses participantes relatam histórias de aprendizagem da língua inglesa que contêm elementos de insucesso e de dificuldades, o que pode ter um impacto na imagem que constroem de si mesmos como aprendizes. O selfideal na L2 é, como explicam Csizér e Kormos (2009), uma auto-imagem que o aprendiz constrói e que revela sua vontade de se tornar um falante competente na L2. Essa autoimagem, que tem na base elementos tais como a integratividade, a instrumentalidade e as atitudes positivas em relação à $\mathrm{L} 2$, é o fator primordial no surgimento e na sustentação da motivação durante o processo de aprendizagem. Através dos excertos, é possível notar a desaprovação que têm de si mesmos como aprendizes.

Acreditamos que a leitura que os participantes fazem de suas experiências de aprendizagem da L2, tal como expressas em suas narrativas, possa ser um obstáculo na consolidação de seu self-ideal em língua inglesa, na sustentação de sua motivação e, em última análise, no desenvolvimento de sua competência comunicativa. É necessário salientar que, no estágio em que esses aprendizes se encontram, a variável atitudes - um antecedente da integratividade - parece estar mais saliente que a variável integratividade (o principal antecedente da motivação e elemento fundamental do self-ideal). Este dado nos permite argumentar, então, que os participantes parecem estar no curso correto: da atitude positiva, para a integratividade, para o self-ideal e motivação que conduza ao desenvolvimento da competência na L2.

Cadernos do IL. Porto Alegre, n. ${ }^{\circ} 38$, junho de 2009. p. $22-42$. 


\section{CONCLUSÕES}

Uma crença bem estabelecida entre alunos e professores de L2 é a de que a condição de imersão oferece o cenário ideal para a aprendizagem. De fato, essa condição reúne elementos que podem otimizar a aprendizagem e o desenvolvimento da interlíngua. Entretanto, como vimos, mesmo em situação de imersão, não é possível garantir quantidade e qualidade de exposição ao insumo linguístico na L2 e esse fator parece estar de certa forma relacionado à construção do self-ideal do aprendiz na medida em que afeta suas experiências de aprendizagem no contexto de imersão. Somadas às experiências negativas anteriores à imersão, as experiências atuais retardam a criação e a consolidação do selfideal do aprendiz e, conseqüentemente, seu grau de motivação. Atitudes positivas em relação à língua e à comunidade de falantes são fatores importantes, mas não são suficientes para a definição do self-ideal.

De que forma podemos garantir que o self-ideal do aprendiz de L2 seja bem definido? Dörnyei (2009) esclarece que o professor tem um papel fundamental no processo de construção do self-ideal, já que é responsável por criar ambientes favoráveis à aprendizagem da L2, e isso inclui dar conta dos aspectos afetivos do aprendiz. Sozinhos, aprendizes de L2 provavelmente levarão mais tempo para ganhar consciência de que o fator "identidade" é um elemento importante no processo de aprendizagem, que se relaciona de maneira complexa com outros elementos, inclusive com a motivação, e que pode determinar o sucesso ou o insucesso do processo. O professor, nesse sentido, pode intervir de maneira decisiva e exercer um maior grau de controle sobre uma variável de natureza flutuante e instável como é a motivação humana.

Com o presente estudo esperamos ter demonstrado que o construto motivação, por muito tempo tomado como uma variável quase inteiramente cognitiva, está relacionado de forma complexa à questões de identidade do aprendiz. O estudo tenta contribuir para a renovação da pesquisa sobre motivação e aprendizagem de L2 e olha para uma população ainda pouco estudada na área de aquisição no Brasil: imigrantes trabalhadores brasileiros em situação de imersão. Entre as várias limitações do estudo, apontamos o número de participantes, o questionário sobre motivação e a duração da coleta de dados. Pesquisas futuras devem ser conduzidas com uma amostra maior e mais representativa, incluindo participantes de outras faixas etárias e grupos sociais, e devem aprimorar o questionário sobre motivação, complementando-o com outros instrumentos além de narrativas e, se possível, adotando formatos longitudinais.

Cadernos do IL. Porto Alegre, n. ${ }^{\circ} 38$, junho de 2009. p. 22-42. 


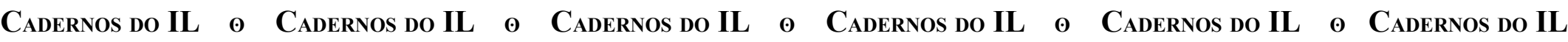

\section{REFERÊNCIAS}

COTTERALL, Sara. Passion and persistence: learning English in Akita. In: KALAJA, Paula; MENEZES, Vera; BARCELOS, Ana Maria (Org.). Narratives of learning and teaching EFL. Londres: Palgrave MacMillan, 2008. p. 113-127.

CSIZÉR, Kata; DÖRNEY, Zoltán. Language learners' motivational profiles and their motivated learning behaviour. Language Learning, v. 55, n. 4, p. 613-659, 2005.

CSIZÉR, Kata; KORMOS, Judit. Learning experiences, selves and motivated learning behaviour: a comparative analysis of structural models for Hungarian secondary and university learners of English. In: DÖRNEY, Zoltán; USHIODA, Ema (Org.). Motivation, language identity and the L2 self. Bristol: Multilingual Matters, 2009. p. 98-119.

DÖRNEY, Zoltán; SKEHAN, Peter. Individual differences in second language learning. In: DOUGHTY, Catherine; LONG, Michael (Org.), The handbook of second language acquisition. Oxford: Blackwell, 2003. p. 589-630.

DÖRNEY, Zoltán. The psychology of the language learner: Individual differences in second language acquisition. Mahwah, NJ: Lawrence Erlbaum, 2005.

. The L2 Motivational Self System. In: DÖRNEY, Zoltán; USHIODA, Ema (Org.).

Motivation, language identity and the L2 self. Bristol: Multilingual Matters, 2009. p. 9-42.

DÖRNEY, Zoltán; CLÉMENT, Richard.Motivational characteristics of learning different target languages: Results of a nationwide survey. In: DÖRNEY, Zoltán; SCHMIDT, Richard (Org.). Motivation and second language acquisition. Honolulu, HI: University of Hawaii Press, 2001. p. 399-432.

DÖRNEY, Zoltán; CSIZÉR, Kata. Some dynamics of language attitudes and motivation: Results of a longitudinal nationwide survey. Applied Linguistics, v. 23, p. 421-462, 2002.

DÖRNEY, Zoltán; USHIODA, Ema. Motivation, language identities and the L2 self: future research directions. In: DÖRNEY, Zoltán; USHIODA, Ema (Org.). Motivation, language identity and the L2 self. Bristol: Multilingual Matters, 2009. p. 350-356.

GARDNER, Robert; LAMBERT, Wallace. Attitudes and Motivation in Second Language Learning. Rowley, MA: Newbury House, 1972.

GARDNER, Robert. Integrative motivation and second language acquisition. In: DÖRNEY, Zoltán; SCHMIDT, Richard (Org.). Motivation and second language acquisition. Honolulu, HI: University of Hawaii Press, 2001. p. 1-19.

HIGGINS, E. Tory. Self-discrepancy: a theory relating self and affect. Psychological Review, v. 94, p. 319-340, 1987.

ISABELLE-GARCIA, Christina. Study abroad social networks, motivation and attitudes: implications for second language acquisition. In: DUFON, Margaret; CHURCHILL, Eton. (Org.). Language learners in study abroad contexts. Clevedon: Multilingual Matters, 2006. p. 231-258.

KALAJA, Paula; MENEZES, Vera; BARCELOS, Ana Maria (Org.). Narratives of learning and teaching EFL. 1'a. ed. Londres: Palgrave MacMillan, 2008.

Cadernos do IL. Porto Alegre, n. ${ }^{\circ} 38$, junho de 2009. p. 22-42.

http://www.seer.ufrgs.br/cadernosdoil/ 
KORMOS, Judit; CSIZÉR, Kata. Age-related differences in the motivation of learning English as a foreign language: attitudes, selves, and motivated learning behavior. Language Learning, v. 58, n. 2, p. 327-355, 2008.

LONG, Michael; DOUGHTY, Catherine. SLA and cognitive science. In: DOUGHTY, Catherine; LONG, Michael (Org.), The handbook of second language acquisition. Oxford: Blackwell, 2003. p. 866-870.

MARKUS, Hazel; NURIUS, Paula. Possible selves. American Psychologist, v. 41, n. 9, p. 954-969, 1986.

PAIVA, Vera Lucia Menezes de Oliveira e. Multimedia language learning histories. In: KALAJA, Paula; PAIVA, Vera Lúcia Menezes de Oliveira; BARCELOS, Ana Maria (Org.). Narratives of learning and teaching EFL. Londres: Palgrave MacMillan, 2008. p. 199-213. ORTEGA, Lourdes. Understanding second language acquisition. Londres: Hodder Arnold, 2009.PAVLENKO, Aneta. Autobiographic narratives as data in applied linguistics. Applied Linguistics, v. 28, n. 2, p. 163-188, 2007.

ROBINSON, Peter. Learning conditions, aptitude complexes, and SLA: a framework for research and pedagogy. In: ROBINSON, Peter (Org.). Individual differences and instructed language learning. Amsterdam: John Benjamins, 2002. p. 137-158.

RYAN, Stephen. Self and identity in L2 Motivation in Japan: the ideal L2 self and Japanese learners of English. In: DÖRNEY, Zoltán; USHIODA, Ema (Org.). Motivation, language identity and the L2 self. Bristol: Multilingual Matters, 2009. p. 120-143.

SANZ, Cristina. Mind and context in adult second language acquisition. Georgetown: Georgetown University Press, 2005.

USHIODA, Ema; DÖRNEY, Zoltán. Motivation, language identities and the L2 self: A Theoretical overview. In: DÖRNEY, Zoltán; USHIODA, Ema (Org.). Motivation, language identity and the L2 self. Bristol: Multilingual Matters, 2009. p. 1-8.

Cadernos do IL. Porto Alegre, n. ${ }^{\circ} 38$, junho de 2009. p. $22-42$. 
Prezado participante,

\section{APÊNDICE A \\ QUESTIONÁRIO DEMOGRÁFICO}

Por favor responda as perguntas abaixo com suas informações.

Obrigada por sua colaboração!

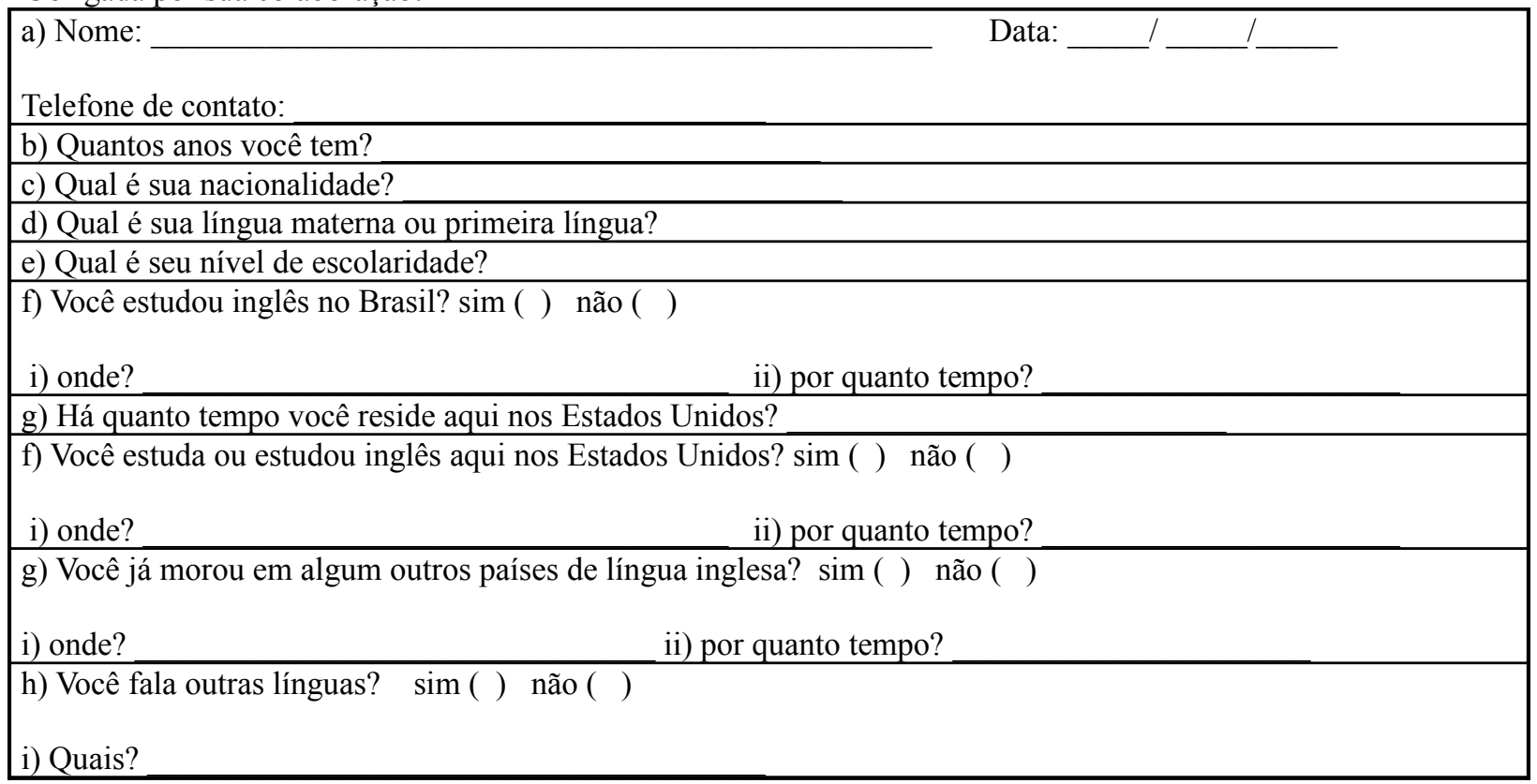

Cadernos do IL. Porto Alegre, n. .38 , junho de 2009. p. 22-42.

http://www.seer.ufrgs.br/cadernosdoil/ 


\section{Questionário}

\section{APÊNDICE B}

Nós gostaríamos de pedir a você para responder as questões a seguir a respeito da aprendizagem de língua estrangeira. Isso não é um teste, logo, não existe resposta "correta" ou "incorreta", você nem precisa colocar o seu nome. Nós estamos interessados em sua opinião. O sucesso desta investigação esta na sinceridade de suas respostas.

Muito obrigado por sua ajuda.

I.Na seção a seguir nós gostaríamos que você respondesse a algumas perguntas simplesmente atribuindo números de 1 a 5 .

$5=$ muito $\quad 4=$ bastante $\quad 3=$ mais ou menos $\quad 2=$ não $\quad 1=$ detesto

Por exemplo, se você gosta MUITO de "hambúrguer", NÃO gosta de "feijão", e DETESTA "espinafre", escreva:

\begin{tabular}{|l|c|c|c|}
\multicolumn{1}{c|}{} & Hambúrguer & Feijão & Espinafre \\
\hline O quanto você gosta destas comidas? & $\mathbf{5}$ & $\mathbf{2}$ & $\mathbf{1}$ \\
\hline
\end{tabular}

Por favor, coloque apenas um número (somente um) em cada espaço, NÃO deixe nenhum espaço vazio..

5 = muito $\quad 4$ = bastante $\quad 3=$ mais ou menos $\quad 2=$ não $\quad 1=$ detesto

\begin{tabular}{|l|l|l|l|l|l|l|}
\hline & & Alemão & Português & Italiano & inglês & Francês \\
\hline 1 & O quanto você gosta dessas línguas? & & & & & \\
\hline 2 & $\begin{array}{l}\text { O quanto você acha que saber essas } \\
\text { línguas ajudaria você a ser uma pessoa } \\
\text { mais sabia? }\end{array}$ & & & & & \\
\hline 3 & $\begin{array}{l}\text { O quão importante você acha que essas } \\
\text { línguas são no mundo atualmente? }\end{array}$ & & & & & \\
\hline 4 & $\begin{array}{l}\text { O quão importante você acha que aprender } \\
\text { essas línguas é para você saber mais sobre } \\
\text { cultura e arte, dos falantes nativos dessas } \\
\text { línguas? }\end{array}$ & & & & & \\
\hline 5 & $\begin{array}{l}\text { Quanto esforço você está determinado a } \\
\text { fazer para aprender essas línguas? }\end{array}$ & & & & & \\
\hline 6 & $\begin{array}{l}\text { O quanto você acha que saber essas } \\
\text { línguas o ajudaria em futuras viagens ao } \\
\text { exterior? }\end{array}$ & & & & & \\
\hline 7 & $\begin{array}{l}\text { O quanto você acha que saber essas } \\
\text { línguas o ajudaria em sua carreira? }\end{array}$ & & & & & \\
\hline 8 & $\begin{array}{l}\text { Quão bem sua mãe/esposa fala essas } \\
\text { línguas? }\end{array}$ & & & & & \\
\hline 9 & $\begin{array}{l}\text { Quão bem seu pai/marido fala essas } \\
\text { línguas? }\end{array}$ & & & & & \\
\hline 10 & $\begin{array}{l}\text { O quanto você gostaria de parecer/soar } \\
\text { com as pessoas que falam essa língua? }\end{array}$ & & & & & \\
\hline
\end{tabular}

Cadernos do IL. Porto Alegre, n. ${ }^{o}$ 38, junho de 2009. p. 22-42.

http://www.seer.ufrgs.br/cadernosdoil/ 


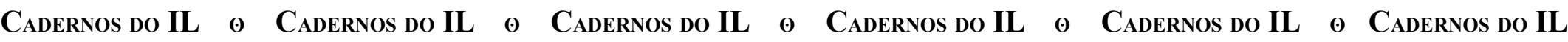

\begin{tabular}{|c|c|c|c|c|c|c|c|}
\hline & & França & Brasil & Alemanha & EUA & Inglaterra & Itália \\
\hline 11 & $\begin{array}{l}\text { O quanto você gostaria de viajar para } \\
\text { esses países? }\end{array}$ & & & & & & \\
\hline 12 & $\begin{array}{l}\text { O quão rico e desenvolvido você acha } \\
\text { que esses países são? }\end{array}$ & & & & & & \\
\hline 13 & $\begin{array}{l}\text { Quão importante você acha que é o papel } \\
\text { desempenhado por esses países no } \\
\text { mundo? }\end{array}$ & & & & & & \\
\hline 14 & $\begin{array}{l}\text { O quanto você gosta de conhecer } \\
\text { estrangeiros desses países? }\end{array}$ & & & & & & \\
\hline 15 & $\begin{array}{l}\text { O quanto você gosta dos filmes feitos } \\
\text { nesses países? (escreva } 0 \text { (zero) se você } \\
\text { nunca viu filmes desses países) }\end{array}$ & & & & & & \\
\hline 16 & $\begin{array}{l}\text { O quanto você gosta dos programas de } \\
\text { TV feitos nesses países? (escreva } 0 \\
\text { (zero) se você nunca viu nenhum } \\
\text { programa de TV desses países) }\end{array}$ & & & & & & \\
\hline 17 & $\begin{array}{l}\text { O quanto você gosta das pessoas que } \\
\text { vivem nesses países? }\end{array}$ & & & & & & \\
\hline 18 & $\begin{array}{l}\text { Qual é a freqüência que você vê filmes/ } \\
\text { programas de TV feitos nesses países? }\end{array}$ & & & & & & \\
\hline 19 & $\begin{array}{l}\text { O quanto você gosta das revistas feitas } \\
\text { nesses países? (escreva } 0 \text { (zero) se você } \\
\text { nunca leu nenhuma revista desses } \\
\text { países) }\end{array}$ & & & & & & \\
\hline 20 & $\begin{array}{l}\text { Qual é a freqüência que você encontra } \\
\text { estrangeiros desses países em lugares, } \\
\text { por exemplo, na rua, restaurantes, lugares } \\
\text { públicos? }\end{array}$ & & & & & & \\
\hline 21 & $\begin{array}{l}\text { O quanto você gosta da música desses } \\
\text { países? } \\
\text { (escreva } 0 \text { (zero) se você nunca ouviu } \\
\text { música desses países) }\end{array}$ & & & & & & \\
\hline
\end{tabular}

Você colocou um número em cada quadrinho? Obrigado!

II. Agora você vai ler afirmações que algumas pessoas concordam e outras não concordam. Nós gostaríamos de saber até que ponto essas afirmações descrevem os seus sentimentos ou as suas próprias situações. Depois de cada afirmação você encontrará 5 quadrinhos. Por favor, marque com um " $X$ " no quadrinho que melhor expressa à VERDADE de acordo com seus sentimentos e suas próprias situações. Por exemplo, se você gosta MUITO de jogar futebol, ponha um "X" no último quadrinho:

\begin{tabular}{|l|l|l|l|l|l|l|l}
\multicolumn{2}{l|}{} & $\begin{array}{c}\text { Com certeza não Não é verdade } \\
\text { é verdade }\end{array}$ & $\begin{array}{c}\text { Parte verdade } \\
\text { parte mentira }\end{array}$ & Quase verdade & \multicolumn{2}{|l}{ Verdade } \\
\hline $\begin{array}{l}\text { Eu gosto muito jogar futebol. } \\
\text { de }\end{array}$ & & & & & \\
\end{tabular}

Cadernos do IL. Porto Alegre, n. .38 , junho de 2009. p. 22-42.

http://www.seer.ufrgs.br/cadernosdoil/ 


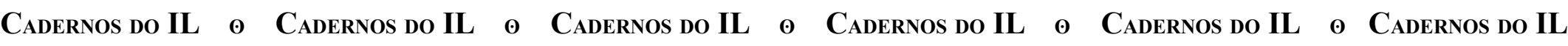

Não tem nem respostas boas nem ruins — Estamos interessados apenas em sua opinião.

\begin{tabular}{|l|l|l|l|l|l|l|}
\hline 22 & $\begin{array}{l}\text { Eu acho que eu sou do tipo de pessoa } \\
\text { que passaria mal se tivesse que } \\
\text { conversar com alguém em outra língua. }\end{array}$ & $\begin{array}{c}\text { Com certeza } \\
\text { não é } \\
\text { verdade }\end{array}$ & $\begin{array}{c}\text { Não é } \\
\text { verdade }\end{array}$ & $\begin{array}{c}\text { Parte verdade } \\
\text { parte mentira }\end{array}$ & $\begin{array}{c}\text { Quase } \\
\text { verdade }\end{array}$ & Verdade \\
\hline 23 & $\begin{array}{l}\text { Pessoas a minha volta acham que saber } \\
\text { outra língua é uma coisa boa. }\end{array}$ & & & & & \\
\hline 24 & $\begin{array}{l}\text { Eu não acho que língua estrangeira seja } \\
\text { uma matéria importante na escola. }\end{array}$ & & & & & \\
\hline 25 & $\begin{array}{l}\text { Ás vezes eu assisto programas na TV a } \\
\text { cabo. }\end{array}$ & & & & & \\
\hline 26 & $\begin{array}{l}\text { Meus pais/marido/esposa não acham que } \\
\text { língua estrangeira seja uma matéria } \\
\text { importante na escola. }\end{array}$ & & & & & \\
\hline 27 & $\begin{array}{l}\text { Eu tenho medo que aprender uma língua } \\
\text { estrangeira vá me fazer sentir menos } \\
\text { brasileiro/a. }\end{array}$ & & & & & \\
\hline 28 & $\begin{array}{l}\text { Aprender uma língua estrangeira é uma } \\
\text { tarefa muito difícil. }\end{array}$ & & & & & \\
\hline
\end{tabular}

III. Finalmente, por favor, responda as perguntas a seguir:

29. Se você pudesse escolher, qual língua estrangeira você começaria a aprender no ano que vem? Por favor, escreva três línguas em ordem de importância. Comece com a mais importante.

1.

2.

3.

30. Circule o seu sexo: masculino feminino

31. Que língua(s) estrangeira(s) você está aprendendo agora?

32. Você aprendeu alguma língua estrangeira na escola?

33. Se SIM, quais?

34. Qual idade você tinha quando você começou a aprender uma língua estrangeira?

35. Você já esteve no exterior por mais de seis meses?

36. Se SIM, onde?

Cadernos do IL. Porto Alegre, n. ${ }^{\circ} 38$, junho de 2009. p. $22-42$.

http://www.seer.ufrgs.br/cadernosdoil/ 